\title{
Eosinophilic Cholecystitis Associated with Eosinophilic Granulomatosis with Polyangiitis
}

\author{
Hiroyuki Ito $^{a} \quad$ Yusuke Mishima $^{a} \quad$ Tsubomi Cho $^{a} \quad$ Naoki Ogiwara $^{a}$ \\ Yoshimasa Shinma ${ }^{a}$ Masashi Yokota ${ }^{a}$ Kazuya Anzai ${ }^{a}$ Shingo Tsuda ${ }^{a}$ \\ Junko Nagata ${ }^{a}$ Seiichiro Kojima ${ }^{a}$ Noriko Sasaki $^{b}$ \\ Takayuki Wakabayashi $^{b}$ Norihito Watanabe ${ }^{a}$ Takayoshi Suzuki ${ }^{a}$ \\ aDepartment of Gastroenterology, Tokai University Hachioji Hospital, Tokyo, Japan; \\ ${ }^{b}$ Department of Rheumatology, Tokai University Hachioji Hospital, Tokyo, Japan
}

\section{Keywords}

Acute cholecystitis · Cerebral hemorrhage · Churg-Strauss syndrome - Eosinophilic cholecystitis · Eosinophilic granulomatosis with polyangiitis

\begin{abstract}
We report a case of eosinophilic cholecystitis associated with eosinophilic granulomatosis with polyangiitis (EGPA) complicated by cerebral hemorrhage. A 60-year-old man presented to a local hospital with a diagnosis of acute cholecystitis, with persistent fever and epigastric pain for 2 weeks. His symptoms persisted despite 3-week hospitalization; therefore, he was transferred to our hospital for further evaluation. Laboratory investigations upon admission showed white blood cells $26,300 / \mu \mathrm{L}$ and significant eosinophilia (eosinophils $61 \%$ ). Abdominal computed tomography revealed no gallbladder enlargement but a circumferentially edematous gallbladder wall. Additional blood test results were negative for antineutrophil cytoplasmic and perinuclear antineutrophil cytoplasmic antibodies; however, immunoglobulin (lg)G and lgE levels were high at $1,953 \mathrm{mg} / \mathrm{dL}$ and $3,040 / \mathrm{IU} / \mathrm{mL}$, respectively. He improved following endoscopic transnasal gallbladder drainage for cholecystitis and was diagnosed with EGPA and received corticosteroid and immunosuppressant combination therapy. The eosinophil count decreased immediately after treatment, and abdominal pain and numbness resolved. He returned with left-sided suboccipital hemorrhage likely attributed to EGPA 6 months after discharge.
\end{abstract}

\begin{tabular}{ll}
\hline & Hiroyuki Ito \\
& Department of Gastroenterology \\
& Tokai University Hachioji Hospital \\
Ishikawa 1838, Hachioji, Tokyo (Japan) \\
hito@is.icc.u-tokai.ac.jp
\end{tabular}




\section{Case Reports in Gastroenterology}

Case Rep Gastroenterol 2020;14:668-674 DOI: 10.1159/000511863

(c) 2020 The Author(s). Published by S. Karger AG, Basel www.karger.com/crg

Ito et al.: Eosinophilic Cholecystitis Associated with Eosinophilic Granulomatosis with Polyangiitis

EGPA is characterized by inflammation of small blood vessels and clinically manifests with an allergic presentation of bronchial asthma, as well as renal dysfunction, interstitial pneumonia, enteritis, and cerebral hemorrhage. Few reports have described cholecystitis as a presenting symptom of EGPA. We report a rare case of such a presentation with added considerations.

(C) 2020 The Author(s)

Published by S. Karger AG, Basel

\section{Introduction}

Eosinophilic cholecystitis is a rare condition that was first reported by Albot et al. [1] in 1949. Previous studies have reported that based on histopathological examination of specimens following cholecystectomy, eosinophilic cholecystitis was diagnosed in $0.84 \%$ of patients. Eosinophilic cholecystitis usually shows good prognosis, and patients with cholecystitis alone improve after cholecystectomy; however, concomitant eosinophilic granulomatosis with polyangiitis (EGPA) necessitates systemic treatment. EGPA is characterized by inflammation of small blood vessels throughout the body and presents with allergic symptoms such as those associated with bronchial asthma. Multiple organs may be affected, and patients may present with renal dysfunction, interstitial pneumonia, enteritis, and cerebral hemorrhage. Few reports have described cholecystitis as a presenting symptom of EGPA. We report a rare case of a patient with this clinical presentation, along with added considerations.

\section{Case Report}

A 60-year-old man was admitted to a local hospital with a diagnosis of acute cholecystitis and fever and epigastric pain that persisted for 2 weeks. The patient did not improve despite 3-week hospitalization at the local hospital; therefore, he was transferred to our hospital for further evaluation. He had a 3-year history of bronchial asthma and sinusitis, and laboratory investigations performed 6 months before hospitalization revealed a significantly high white blood cell count of $9,730 / \mu \mathrm{L}$ with $28 \%$ eosinophils. He denied any relevant family history or allergies. Physical examination on admission showed a temperature of $37.3^{\circ} \mathrm{C}$, heart rate of 90 beats/min, no oral abnormalities, cervical lymphadenopathy, or edema of the extremities. On auscultation, he showed no wheezing and no heart murmur. He complained of pain throughout the abdomen; however, the Murphy sign was negative. His left lower leg was numb; however, we did not observe movement, sensory, or deep sensory disorders or other neurological abnormalities. Laboratory investigations showed the following results: elevated white blood cell $(26,300 / \mu \mathrm{L})$ and eosinophil counts $(61.0 \%)$, serum hemoglobin $12.3 \mathrm{~g} / \mathrm{dL}$, platelets $279,000 / \mu \mathrm{L}$, elevated serum hepatobiliary enzymes (aspartate aminotransferase $74 \mathrm{IU} / \mathrm{L}$, alanine aminotransferase $80 \mathrm{IU} / \mathrm{L}$, lactate dehydrogenase $311 \mathrm{IU} / \mathrm{L}$, alkaline phosphatase 483 $\mathrm{IU} / \mathrm{L}$, gamma-glutamyl transpeptidase $95 \mathrm{IU} / \mathrm{L}$, amylase $93 \mathrm{IU} / \mathrm{L}$, total bilirubin $0.4 \mathrm{mg} / \mathrm{dL}$ ), serum glucose $96 \mathrm{mg} / \mathrm{dL}$, international normalized ratio 1.36, and C-reactive protein 8.14 $\mathrm{mg} / \mathrm{dL}$. Plain abdominal computed tomography revealed no gallbladder enlargement, no stone, and no spread of inflammation to the liver (Fig. 1a). Abdominal ultrasonography revealed that the gallbladder was swollen $(82 \times 30 \mathrm{~mm})$ with slight gallbladder wall thickening $(3 \mathrm{~mm})$, suggesting inflammation (Fig. 1b). Magnetic resonance cholangiopancreatography revealed partial edema of the gallbladder wall attributed to cholecystitis (Fig. 1c).

\section{Karger'=}




\section{Case Reports in Gastroenterology}

Case Rep Gastroenterol 2020;14:668-674

DOI: 10.1159/000511863

(c) 2020 The Author(s). Published by S. Karger AG, Basel www.karger.com/crg

Ito et al.: Eosinophilic Cholecystitis Associated with Eosinophilic Granulomatosis with Polyangiitis

Based on the patient's clinical history and past history of bronchial asthma and sinusitis, we suspected EGPA. Cholecystitis and numbness of the left lower extremity were attributed to eosinophilic cholecystitis and polyneuropathy, respectively. We performed additional blood tests, which showed the following results: antineutrophil cytoplasmic antibodies (ANCA) $1.0 \mathrm{U} / \mathrm{mL}$ and perinuclear ANCA $1.0 \mathrm{U} / \mathrm{mL}$ were both negative; however, serum immunoglobulin (Ig)G (1,953 mg/dL), IgG4 (507 mg/dL), IgE (3,040 IU/mL), IgA (254 mg/dL), and IgM $(143 \mathrm{mg} / \mathrm{dL})$ were elevated. We performed endoscopic transnasal gallbladder drainage for cholecystitis (Fig. 1d), which improved following drainage; therefore, the drainage tube was removed 5 days after placement. Upper and lower gastrointestinal endoscopy was performed, and multiple aphthous erosions were observed in the descending part of the duodenum and the ascending colon (Fig. 2a, b). Histopathological examination of duodenum specimens showed aphthae with eosinophils localized around microvessels (Fig. 2c). Immunohistochemical examination was immunonegative for IgG4 (Fig. 2d). Histopathological evaluation of nasal mucosa specimens showed inflammatory cell infiltrates mainly containing plasma cells and lymphocytes; however, no granuloma including vasculitis was observed (Fig. 2e). Although typical histopathological features, such as perivascular eosinophilic infiltration and granulomatous changes, were not observed, he met the following diagnostic criteria: (1) a history of bronchial asthma or allergic rhinitis, (2) eosinophilia, and (3) peripheral neuritis. Therefore, he was diagnosed with EGPA. Corticosteroid therapy was initiated at a dose of 40 $\mathrm{mg}$, which was subsequently reduced to $30 \mathrm{mg}$ after 4 weeks. Cyclophosphamide was administered as an immunosuppressant at a dose of $700 \mathrm{mg}$ on the 7th and 35th days after prednisolone administration. His eosinophil count decreased, and abdominal pain and numbness of the lower extremities disappeared immediately after treatment initiation. Six months after discharge, the patient was re-admitted to our hospital on an emergency basis with a right visual field disorder. He was diagnosed with left-sided suboccipital hemorrhage (Fig. 2f), suspected to be associated with EGPA, and underwent 17-day conservative decompression therapy. The corticosteroid dose was gradually tapered to $10 \mathrm{mg}, 15$ months after initial treatment, and the therapy has been continued.

\section{Discussion}

Eosinophilic cholecystitis is a rare condition that was first reported by Albot et al. [1] in 1949. Yeom et al. [2] analyzed 3,539 histopathological specimens obtained after cholecystectomy and observed 30 patients $(0.84 \%)$ with eosinophilic cholecystitis, of which 6 patients $(0.16 \%)$ showed significant preoperative eosinophilia. Eosinophilic cholecystitis is diagnosed based on histopathological findings and is defined as inflammatory cell infiltrates in tissue specimens showing $\geq 90 \%$ eosinophils [3]. Cholecystectomy performed in the acute phase proves eosinophilic infiltration, and if the peripheral blood eosinophil count normalizes with corticosteroid treatment, eosinophilic infiltration may not be detected in excised specimens $[4,5]$. Our patient did not meet the diagnostic criteria for this condition because cholecystitis improved with endoscopic treatment. However, steroid therapy successfully treated cholecystitis with a significant reduction in eosinophilia; therefore, we strongly suspected eosinophilic cholecystitis in this case. Eosinophilic cholecystitis may be drug induced following the administration of L-tryptophan, penicillin, cephem, and erythromycin or may occur secondary to parasitic infestations, such as those caused by liver fluke and roundworm, in addition to EGPA, and these conditions should be excluded [6]. Imaging findings in patients with

\section{Karger'=}




\section{Case Reports in Gastroenterology}

Case Rep Gastroenterol 2020;14:668-674

DOI: 10.1159/000511863

c) 2020 The Author(s). Published by S. Karger AG, Basel www.karger.com/crg

Ito et al.: Eosinophilic Cholecystitis Associated with Eosinophilic Granulomatosis with Polyangiitis

eosinophilic cholecystitis include edema and thickening of the gallbladder wall, as well as pericholecystic fluid accumulation (similar to that observed in cases of cholecystitis) [7-10]. Shakov et al. [11] reported that 18 of 24 patients (75\%) with eosinophilic cholecystitis showed acalculous cholecystitis, which was higher than the prevalence of acalculous cholecystitis (2$15 \%$ ) routinely observed in clinical practice. Eosinophilic cholecystitis is associated with good prognosis, and cholecystitis alone can be successfully treated with cholecystectomy; however, concomitant EGPA necessitates systemic treatment with corticosteroids [12].

EGPA, a form of vasculitis, was previously called allergic granulomatous angiitis or ChurgStrauss syndrome but was renamed at the 2012 international conference $[13,14]$. It most commonly affects those aged 30-60 years, and the male:female ratio is 4:6. Clinically, EGPA presents with asthma and allergic rhinitis as antecedent symptoms, followed by features of vasculitis and eosinophilia, fever, weight loss, mononeuritis (manifesting with frequent abdominal and extremity pain), gastrointestinal ulcers, myocardial infarction, epicarditis, and cerebral hemorrhage [15]. Patients with mononeuritis may show persistent sensory and motor disorders despite improvement in acute symptoms. Laboratory data typically show eosinophilia $(\geq 5,000$ cells $/ \mu \mathrm{L})$, leukocytosis $(\geq 10,000$ cells $/ \mu \mathrm{L})$, a high platelet count $(\geq 400,000 / \mu \mathrm{L})$, elevated serum IgE levels $(\geq 600 \mathrm{U} / \mathrm{mL})$, and a positive rheumatoid factor. Notably, myeloperoxidase ANCA (an ANCA subtype) shows positive results in approximately $50 \%$ of patients [16]. Histopathological examination in most patients shows leukocytoclastic vasculitis associated with granulomatous or fibrinoid degeneration of small blood vessels with marked perivascular eosinophilic infiltration, and occasional extravascular granulomas [17]. The diagnostic criteria include the following: (1) bronchial asthma or allergic rhinitis, (2) eosinophilia, or (3) fever, weight loss, polyneuropathy, gastrointestinal bleeding, polyarthralgia, myalgia, and/or purpura. EGPA is confirmed in patients who present with criteria (1) and (2) followed by features of vasculitis, or in patients in whom all 3 criteria are satisfied and the diagnosis can be confirmed by histopathological evaluation [18]. In our patient, fever, weight loss, and polyneuropathy occurred after an initial presentation of bronchial asthma, allergic rhinitis, and eosinophilia, which fulfilled the diagnostic criteria for EGPA. Corticosteroids are used to treat mild cases; however, combination therapy with corticosteroids and immunosuppressants is necessary in severe cases. Our patient was categorized as a severe case owing to symptomatic polyneuropathy and, therefore, received combination therapy [19]. Neuroinflammatory conditions manifesting with abdominal and extremity pain are occasionally refractory to corticosteroids, and high-dose intravenous immunoglobulin therapy is used in such cases [20].

Both eosinophilic cholecystitis and EGPA show relatively good prognosis, and treatment leads to remission in approximately $90 \%$ of patients. However, our patient developed cerebral hemorrhage (probably attributed to EGPA) during remission, 6 months after diagnosis. Patients with eosinophilic cholecystitis associated with EGPA may develop delayed systemic complications secondary to vasculitis; therefore, careful follow-up is important even after treatment.

\section{Statement of Ethics}

This article does not contain any studies with human participants performed by any of the authors. Informed consent from the patient for publication including images was obtained

\section{Karger'=}




\section{Case Reports in Gastroenterology}

Case Rep Gastroenterol 2020;14:668-674

DOI: $10.1159 / 000511863$

(c) 2020 The Author(s). Published by S. Karger AG, Basel www.karger.com/crg

Ito et al.: Eosinophilic Cholecystitis Associated with Eosinophilic Granulomatosis with Polyangiitis

using the hospital default informed consent form. The research was conducted ethically in accordance with the World Medical Association Declaration of Helsinki.

\section{Conflict of Interest Statement}

The authors have no conflicts of interest to declare.

\section{Funding Sources}

The authors received no financial support for the research, authorship, and/or publication of this article.

\section{Author Contributions}

H.I., S.T., J.N., S.K., N.S., T.W., and N.W. contributed to the patient's medical treatment. H.I. is the primary investigator and contributed to conceptualization, data collection, and drafting of the manuscript. All authors have read and approved the final version of the manuscript.

\section{References}

1 Albot G, Poilleux Olivier C, Libaude H, Cascarigny P. Les cholecystites a eosinophils [in French]. Presse Med. 1949;57(39):558-9.

2 Yeom SS, Kim HH, Kim JC, Hur YH, Koh YS, Cho CK, et al. Peripheral eosinophilia - is it a predictable factor associated with eosinophilic cholecystitis? Korean J Hepatobiliary Pancreat Surg. 2012 May;16(2):65-9.

3 Dabbs DJ. Eosinophilic and lymphoeosinophilic cholecystitis. Am J Surg Pathol. 1993 May;17(5):497-501.

4 Sánchez-Pobre P, López-Ríos Moreno F, Colina F, Yela C, Manzano M, Rodríguez S, et al. [Eosinophilic cholecystitis: an infrequent cause of cholecystectomy]. Gastroenterol Hepatol. 1997 Jan;20(1):21-3.

5 Felman RH, Sutherland DB, Conklin JL, Mitros FA. Eosinophilic cholecystitis, appendiceal inflammation, pericarditis, and cephalosporin-associated eosinophilia. Dig Dis Sci. 1994 Feb;39(2):418-22.

6 Hepburn A, Coady A, Livingstone J, Pandit N. Eosinophilic cholecystitis as a possible late manifestation of the eosinophilia-myalgia syndrome. Clin Rheumatol. 2000;19(6):470-2.

7 Punia RP, Arya S, Jain P, Bal A, Mohan H. Eosinophilic and lympho-eosinophilic cholecystitis. Indian J Gastroenterol. 2003 Jul-Aug;22(4):153-4.

8 Suzuki M, Nabeshima K, Miyazaki M, Yoshimura H, Tagawa S, Shiraki K. Churg-Strauss syndrome complicated by colon erosion, acalculous cholecystitis and liver abscesses. World J Gastroenterol. 2005 Sep;11(33):5248-50.

9 Nishie M, Tomiyama M, Kamijo M, Kannari K, Tanosaki M, Baba M, et al. Acute cholecystitis and duodenitis associated with Churg-Strauss syndrome. Hepatogastroenterology. 2003 Jul-Aug;50(52):998-1002.

10 Tatsukawa H, Nagano S, Umeno Y, Oribe M. Churg-strauss syndrome with cholecystitis and renal involvement. Intern Med. 2003 Sep;42(9):893-6.

11 Shakov R, Simoni G, Villacin A, Baddoura W. Eosinophilic cholecystitis, with a review of the literature. Ann Clin Lab Sci. 2007;37(2):182-5.

12 Tajima K, Katagiri T. Deposits of eosinophil granule proteins in eosinophilic cholecystitis and eosinophilic colitis associated with hypereosinophilic syndrome. Dig Dis Sci. 1996 Feb;41(2):282-8.

13 Churg J, Strauss L. Allergic granulomatosis, allergic angiitis, and periarteritis nodosa. Am J Pathol. 1951 MarApr;27(2):277-301.

14 Samson M, Puéchal X, Devilliers H, Ribi C, Cohen P, Stern M, et al.; French Vasculitis Study Group. Long-term outcomes of 118 patients with eosinophilic granulomatosis with polyangiitis (Churg-Strauss syndrome) enrolled in two prospective trials. J Autoimmun. 2013 Jun;43:60-9. 


\section{Case Reports in Gastroenterology}

\begin{tabular}{l|l}
\hline Case Rep Gastroenterol 2020;14:668-674 \\
\hline DOI: 10.1159/000511863 & $\begin{array}{l}\text { @ 2020 The Author(s). Published by S. Karger AG, Basel } \\
\text { www.karger.com/crg }\end{array}$ \\
\hline
\end{tabular}

Ito et al.: Eosinophilic Cholecystitis Associated with Eosinophilic Granulomatosis with Polyangiitis

15 Guillevin L, Cohen P, Gayraud M, Lhote F, Jarrousse B, Casassus P. Churg-Strauss syndrome. Clinical study and long-term follow-up of 96 patients. Medicine (Baltimore). 1999 Jan;78(1):26-37.

16 Watts R, Lane S, Hanslik T, Hauser T, Hellmich B, Koldingsnes W, et al. Development and validation of a consensus methodology for the classification of the ANCA-associated vasculitides and polyarteritis nodosa for epidemiological studies. Ann Rheum Dis. 2007 Feb;66(2):222-7.

17 Sada KE, Amano K, Uehara R, Yamamura M, Arimura Y, Nakamura Y, et al.; Research Committee on Intractable Vasculitides, the Ministry of Health, Labour, Welfare of Japan. A nationwide survey on the epidemiology and clinical features of eosinophilic granulomatosis with polyangiitis (Churg-Strauss) in Japan. Mod Rheumatol. 2014 Jul;24(4):640-4.

18 Lanham JG, Elkon KB, Pusey CD, Hughes GR. Systemic vasculitis with asthma and eosinophilia: a clinical approach to the Churg-Strauss syndrome. Medicine (Baltimore). 1984 Mar;63(2):65-81.

19 Masi AT, Hunder GG, Lie JT, Michel BA, Bloch DA, Arend WP, et al. The American College of Rheumatology 1990 criteria for the classification of Churg-Strauss syndrome (allergic granulomatosis and angiitis). Arthritis Rheum. 1990 Aug;33(8):1094-100.

20 Ohnuki Y, Moriya Y, Yutani S, Mizuma A, Nakayama T, Ohnuki Y, et al. Eosinophilic Granulomatosis with Polyangiitis (Churg-Strauss Syndrome) Complicated by Perforation of the Small Intestine and Cholecystitis. Intern Med. 2018 Mar;57(5):737-40.
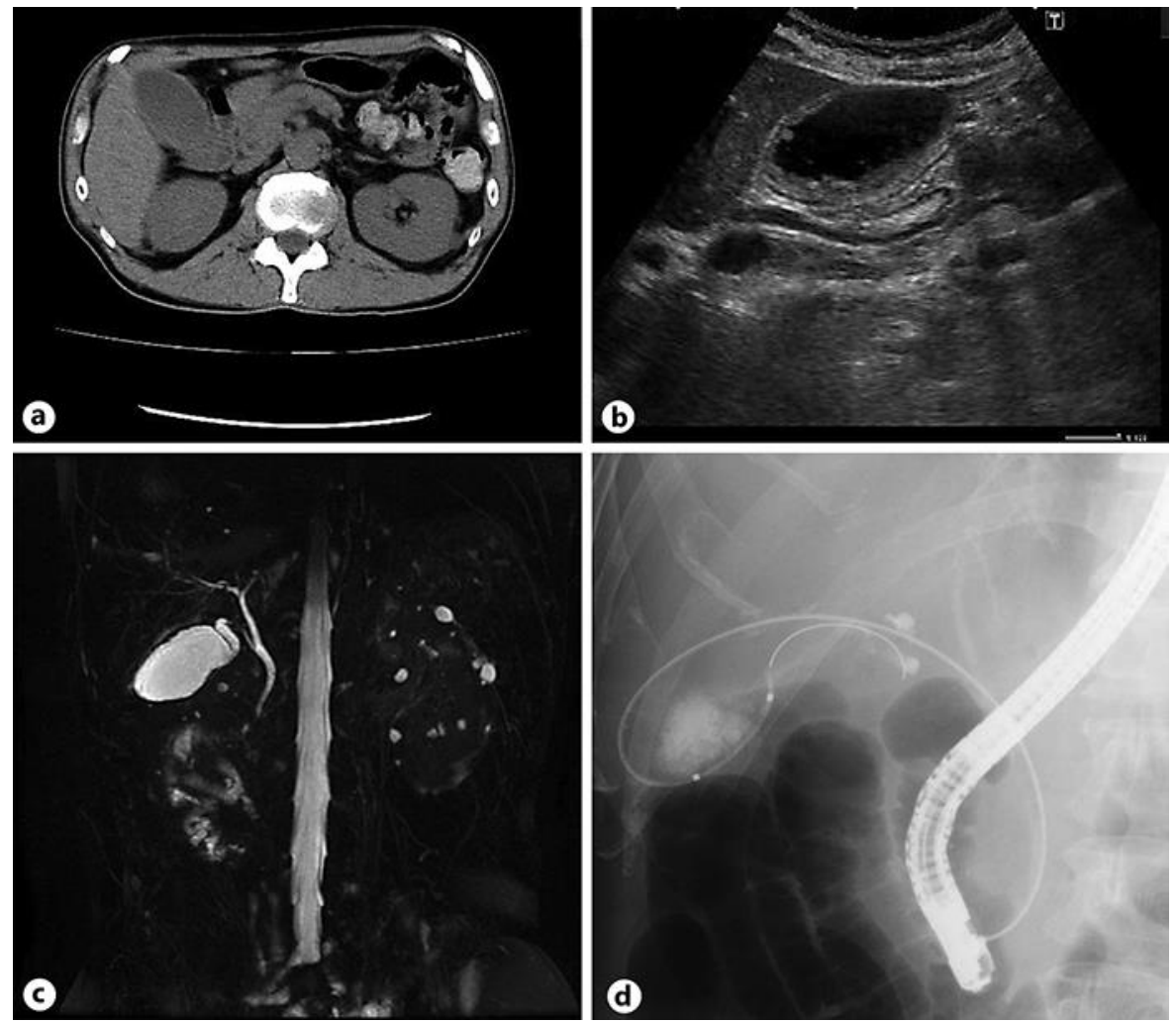

Fig. 1. a Plain abdominal computed tomography revealed no gallbladder enlargement, no stone, and no spread of inflammation to the liver. $\mathbf{b}$ Abdominal ultrasonography revealed that the gallbladder was swollen with slight gallbladder wall thickening. c Magnetic resonance cholangiopancreatography revealed partial edema of the gallbladder wall. $\mathbf{d}$ Endoscopic transnasal gallbladder drainage for cholecystitis was performed.

\section{Karger'=}




\section{Case Reports in Gastroenterology}
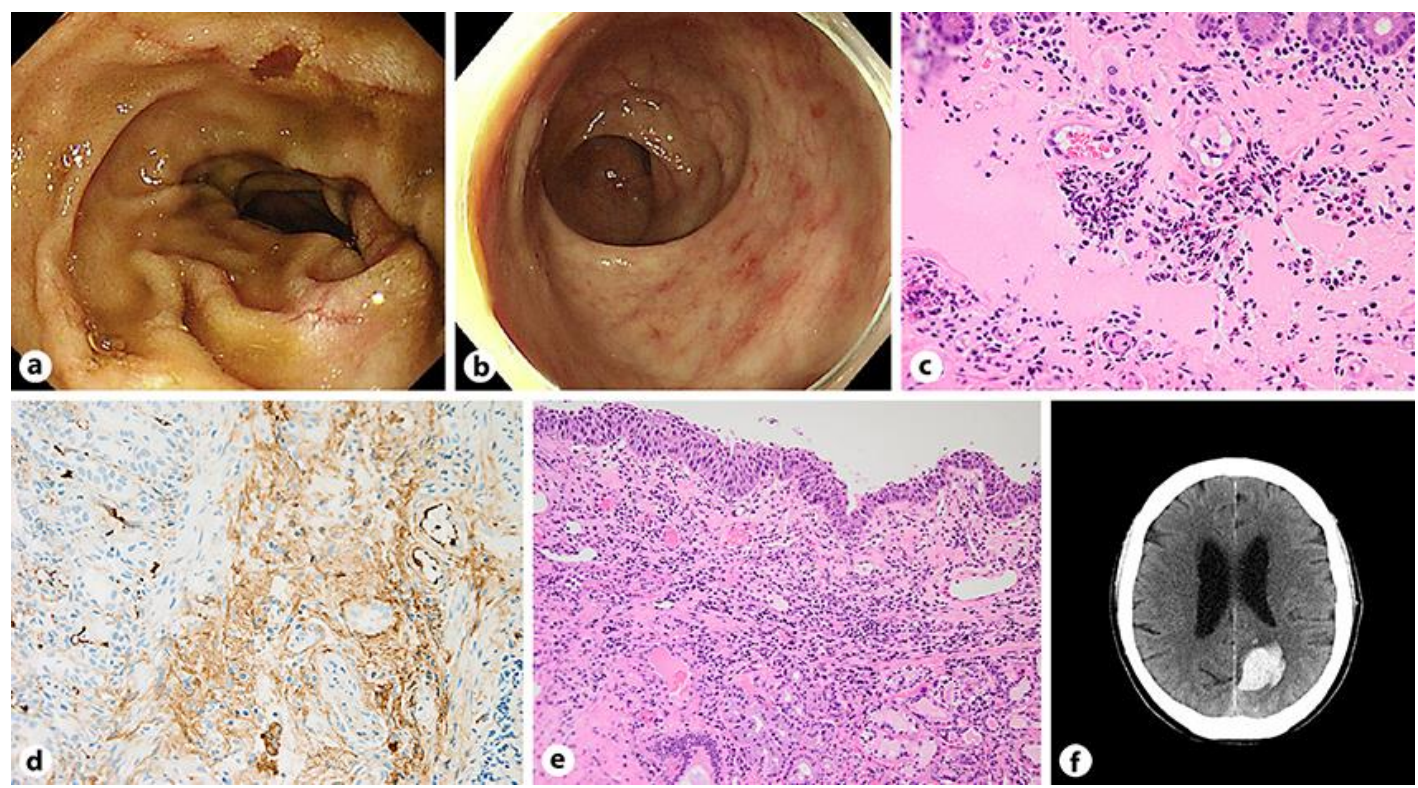

Fig. 2. a Multiple aphthous erosions were observed in the descending part of the duodenum. b Multiple aphthous erosions were observed in the ascending colon. c Histopathological examination of duodenum specimens showed aphthae with eosinophils localized around microvessels. $\mathbf{d}$ Immunohistochemical examination was immunonegative for IgG4. e Histopathological evaluation of nasal mucosa specimens showed inflammatory cell infiltrates mainly containing plasma cells and lymphocytes; however, no granuloma including vasculitis was observed. $\mathbf{f}$ Head computed tomography revealed a left-sided suboccipital hemorrhage. 